\title{
MEMBRANE CHARACTERIZATION
}

\section{Khulbe KC, Feng CY and Matsuura T}

Industrial Membrane Research Laboratory, Chemical and Biological Engineering Department, University of Ottawa, Ottawa, K1N 6N5, Canada

Keywords: Methods for the membrane characterization, morphology of membrane surface, pore size measurement and distribution,, bubble gas transport, mass transport, mercury intrusion; adsorption-desorption, gas liquid equilibrium, contact angle, SEM, TEM, AFM, FTIR, Raman spectroscopy, ESR, NMR, WAXS, XPS, SANS, Positronium annihilation lifetime spectroscopy , ultrasonic spectra.

\section{Content}

1. Introduction

2. Pore Size Distribution Measurement

2.1. Bubble Gas Transport Method

2.2. Mercury Intrusion Porosimetry

2.3. Adsorption-Desorption Method (Barett-Joyner-Halenda (BJH) Method) [7]

2.4. Gas Liquid Equilibrium Method (Permporometry)

2.4.1. Liquid Displacement Permporometry (LDP) [11]

2.4.2. Diffusional Permoporometry (DP) [17]

2.5. Liquid Solid Equilibrium Method (Thermoporometry)

2.6. Gas Permeability Method

2.7. Mass Transportation

3. Membrane morphology

3.1. Microscopic Method

3.1.1. Scanning Electron Microscopy (SEM) and Transmission Electron Microscopy (TEM)

3.1.2. Atomic Force Microscopy

3.2. Spectroscopic Method

3.2.1. Infrared (IR) and Fourier Transform Infrared (FTIR) Spectroscopy

3.2.2. Raman Spectroscopy (RS)

3.2.3. Electron Spin Resonance (ESR)

3.2.4. Nuclear Magnetic Resonance (NMR)

3.2.5. Wide Angle X-ray Scattering (WAXS)

3.2.6. X-ray Photoelectron Spectroscopy (XPS)

3.2.7. Small Angle Neutron Scattering (SANS)

3.2.8. Positronium Annihilation Lifetime Spectroscopy (PALS)

3.2.9. Ultrasonic Spectroscopy

4. Other Techniques

4.1. Contact Angle

4.2. Surface Charge (Zeta Potential)

4.3. Differential Scanning Calorimetry (DSC) and Thermogravimetry (TGA)

5. Mechanic properties

5.1. Tensile Strength

5.2. Young's Modulus of Elasticity

6. Conclusion 


\author{
Glossary \\ Bibliography \\ Biographical Sketches
}

\title{
Summary
}

Nowadays, many researchers are working on membrane development, either for membrane water treatment or membrane gas separation. Many of them are attempting to find the cause and affect relationship between membrane fabrication-membrane morphology-membrane performances. The ultimate goal of the research is to provide a rational guideline for membrane fabrication conditions to achieve some specific membrane morphology, which enables the desired separation performance. For this reason, membrane morphology characterization is one of the indispensable components of membrane research.

Membrane manufacturers should also specify the membranes they provide by various characterization parameters such as pore size and pore size distributions and solute and particle rejections. By knowing these parameters, membrane users are able to choose conveniently those membranes that satisfy their requirements and to decide the conditions under which the membranes are used. It is needless to say that the ideal characterization method should be non-destructive, accurate, and repeatable and fast and also should give a maximum possible number of data. To this end, many methods have been devised.

This chapter focuses on the methods to characterize membranes for pressure driven processes such as reverse osmosis, nano-filtration, ultrafiltration, microfiltration, membrane gas and vapor separation, pervaporation etc. The examples shown in the article are mostly for the characterization of synthetic polymeric membranes but the applications of the methods are not necessarily limited to those.

Even though there are many characterization methods available, they are generally classified into the following categories

- Conventional physical methods to determine pore size and pore size distribution

- Micrographic methods to have photographical images

- Spectroscopic methods to know the membrane structure in its molecular level

- Methods to obtain bulk properties of membranes such as thermal and mechanical properties

- Other methods such as contact angle and zeta potential measurement

In this chapter, attempts are made to show principles and examples for each method.

\section{Introduction}

The development of asymmetric membranes for seawater desalination with a thin selective layer supported by a porous layer opened up a new avenue in membrane separation technology by Loeb and Sourirajan during the nineteen sixties [1]. Over the past 50 years membrane separation technology has grown into an annual several billiondollar industry world wide. There are a number of membrane separation processes 
currently being used. Typical examples are: reverse osmosis (RO), microfiltration (MF), nanofiltration (NF), ultrafiltration (UF), forward osmosis (FO), pervaporation (PV), vapor separation (VP), membrane gas separation and membrane distillation.(MD).

Nowadays, many researchers are working on membrane development, either for membrane water treatment or membrane gas separation, and all of them attempt to find the cause and affect relationship between membrane fabrication-membrane morphology-membrane performances. The ultimate goal of the research is to be able to choose fabrication conditions to achieve membrane morphology, which is designed to enable the desired separation performance. In this regard, membrane morphology characterization is one of indispensable components of membrane research.

There are a number of methods to specify the membrane morphology. The classical way of characterizing the membrane is to determine pore size and pore size distribution of the membrane. The pore sizes determined by different methods do not necessarily agree with each other but they usually show some common trends. Currently, with the advancement of sophisticated physical instrument, researchers tend to identify the environment of the permeating molecules more on a molecular level. As the digital quantification of the instrument progresses in sub-nano scale, the difference between measurement of pore size and specification of the segmental distance in macromolecules is disappearing. In other words, the measurement of sub-nano scale pore size is generally accepted.

Another important trend in membrane characterization is that emphasis is more on the characterization of membrane surface morphology. It is in a way natural since membrane separation is fundamentally the reflection of surface phenomena, as manifested by the structure of integrally skinned asymmetric membranes and thin-film composite membranes. This trend has also been enhanced by the advancement of modern physical instrument such as atomic force microscopy (AFM) and X-ray photoelectron microscopy (XPS).

Yet, characterization of bulk membrane properties by conventional methods should not be ignored. The thermal, mechanical and chemical properties are examples of those.

The objective of this chapter is to make a comprehensive overview of different membrane characterization methods. For each method, the principle, instrumental method and examples that are particularly relevant to the membrane characterization are shown.

\section{Pore Size Distribution Measurement}

\subsection{Bubble Gas Transport Method}

This method is based on the measurement of the pressure necessary to blow air through a water-filled porous membrane [2]. The method so developed has been thoroughly used to characterize membranes and also is called the bubble point method. This method is only able to discriminate maximum pore size present in the pore distribution, corresponding to the minimum pressure necessary to blow the firstly observed air 
bubble.

Figure 1 shows a schematic drawing of the test apparatus and the principle of the bubble-point method is depicted schematically in Figure 2, from which it can be seen that the liquid on the top of the membrane wets the latter. The bottom of the membrane is in contact with air and the air pressure is gradually increased until bubbles of air penetrate through the membrane at a certain pressure.

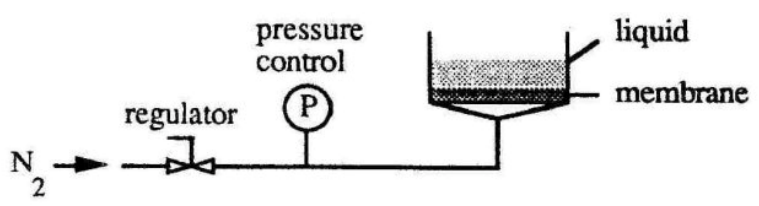

Figure1. Schematic drawing of a bubble-point test apparatus

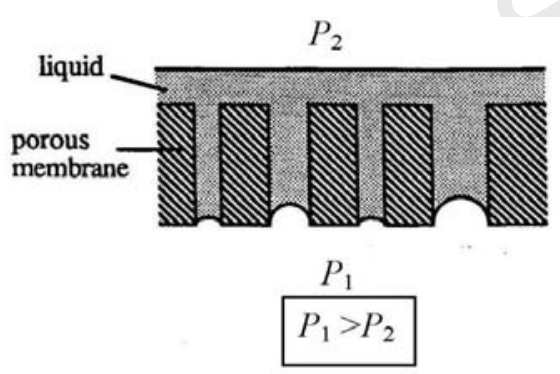

Figure2. The principle of the bubble-point method

An air bubble will penetrate through a pore of radius $r_{P}$ when the transmembrane pressure difference $\Delta P=P_{1}-P_{2}$ given by the following Laplace equation is reached.

$$
r_{P}=\frac{2 \gamma \cos \theta}{\Delta P}
$$

In Eq. (1), $\gamma$ is the surface tension at the liquid/air interface and $\theta$ is the contact angle. When a commercial wetting fluid Galwick ${ }^{\mathrm{TM}}$ (Porous Materials Inc. USA) is used, the pore is wetted spontaneously and the contact angle of $0^{\circ}$ can be assumed. The surface tension of the liquid is $15.9 \times 10^{-3} \mathrm{~N} / \mathrm{m}$.

When $\theta=0^{\circ}$, the Laplace equation is reduced to

$$
r_{\mathrm{p}}=\frac{2 \gamma}{\Delta P}
$$

which is called Cantor's equation.

Penetration will first occur through the largest pores and since the pressure difference is known, the pore radius can be calculated from Eq. (1). It is also possible to obtain pore 
size distribution by performing this technique by a stepwise increase of pressure. This will be explained later on as permporometry.

Using water as wetting fluid, the pressure that corresponds to the pore radius of $0.01 \mu \mathrm{m}$, will become 145 bar because the surface tension of water is as high as $72.3 \times 10^{-3} \mathrm{~N} / \mathrm{m}$ (and assuming $0^{\circ}$ contact angle). To avoid these high pressures, Bechhold [3] and Erbe [4] used two different liquids, instead of an air-liquid interface, reducing appreciably the surface tension. For example, using isobutyl alcohol-water interface, the measurement of pore sizes 40 times lowers is achieved, as compared with air-water interface. (This method is explained more in detail as liquid displacement method later on.) The method has been improved for both liquid-gas interfaces [5], and liquid-liquid ones [6], allowing the evaluation of pore sizes corresponding to a range of porous material, and is very well commercialized. The bubble point method is an easy, fast and inexpensive method to determine the maximum pore size and pore size distribution of membranes.

\subsection{Mercury Intrusion Porosimetry}

Mercury intrusion porosimetry is used extensively for the characterization of various aspects of porous media, including porous membranes and powders. Mercury porosimetry is applicable to pores from $30 \AA$ up to $900 \AA$ in diameters. It is well commercialized. Mercury intrusion porosimetry involves placing the sample in a special sample cup (penetrometer), surrounding the sample with mercury. Mercury is a nonwetting liquid to most materials and resists entering voids, doing so only when pressure is applied. The pressure at which mercury enters a pore is inversely proportional to the size of the opening to the void. As mercury is forced to enter pores within the sample material, it is depleted from a capillary stem reservoir connected to the sample cup. The incremental volume depleted after each pressure change is determined by measuring the change in capacitance of the stem. This intrusion volume is recorded with the corresponding pressure or pore size. By this technique, both pore size and pore size distribution can be determined.

The relationship of pressure and pore size is given by the Laplace equation (1). As mercury does not wet the membrane (since its contact angle is greater than $90^{\circ}$ and $\cos \theta$ will have a negative value), Eq. (1) is modified as follows:

$r_{\mathrm{p}}=-\frac{2 \gamma \cos \theta}{P}$

The contact angle of mercury with polymeric material is often $141.3^{\circ}$ and the surface tension at the $\mathrm{Hg} /$ air interface is $0.48 \mathrm{~N} / \mathrm{m}$. Hence Eq. (3) will be

$$
r_{\mathrm{p}}=\frac{7492}{P}
$$

where $r_{\mathrm{p}}$ is expressed in $\mathrm{nm}$ and $P$ in bar.

Since the volume of mercury can be determined very accurately, pore size distributions 
can be determined quite precisely. In Eq. (4), it is assumed that the membranes have capillary pores. As in general, it is not always right, morphology constant must be introduced. Furthermore, very high pressures should be avoided since these may damage the porous structure and lead to an erroneous pore size distribution.

Figure 3 gives a schematic drawing of the results of mercury intrusion experiment.

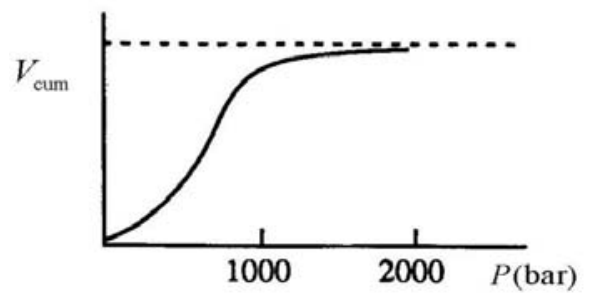

Figure. 3 Cumulative volumes $\left(V_{\text {cum }}\right)$ as a function of the applied pressure

There are few disadvantages of this technique: i) it is expensive and not widely used. ii) it needs high pressure which could damage the surface, and iii) it measures all the pores present in the structure, including dead end pores.

\subsection{Adsorption-Desorption Method (Barett-Joyner-Halenda (BJH) Method) [7]}

Gas adsorption is a popular and commonly used method for characterization of surface and structural properties of porous materials allowing the determination of their surface area, pore volume, pore size distribution and adsorption energy distribution. Nitrogen is often used for the adsorbent gas but other adsorbents such as argon and benzene are also used. According to this method adsorption-isotherm (amount of adsorbed gas versus relative pressure (pressure/saturation vapor pressure of the adsorbent)) is drawn and the data are analyzed by assuming capillary condensation.

The vapor pressure, $p$, of the adsorbent liquid in the pore of radius $r_{\mathrm{p}}$ is given by the following Kelvin equation,

$\ln \frac{p}{p_{0}}=-\frac{2 \gamma V}{r_{\mathrm{p}} R T} \cos \theta$

where $p_{0}$ is the saturation vapor pressure, $\gamma$ is the surface tension of the adsorbent liquid, $V$ is the molar volume of the adsorbent liquid, $R$ is the universal gas constant, $T$ is absolute temperature and $\theta$ is the contact angle. Assuming $\theta=0^{\circ}$, the above equation becomes for the liquid nitrogen,

$r_{\mathrm{p}}=-\frac{4.1}{\log \frac{p}{p_{0}}}$ 
Assuming further all the pores whose radii are smaller than $r_{\mathrm{p}}$ are filled at a given relative pressure $p / p_{0}$, the cumulative pore volume curve versus $r_{\mathrm{p}}$ can be drawn. Often, the thickness of adsorbed layer $t$ is added to $r_{\mathrm{p}}$ obtain above to calculate more precise pore radius.

In reality, the sorption-desorption curves are different due to hysteresis, depending on the pore structure. During analysis it is necessary to decide which branch of the isotherm to use, the adsorption or desorption branch. BJH method was modified by Kruk and Jaroniec in 2000 [8]. This method also is well documented in literature and university text books [2] and well commercialized.

\subsection{Gas Liquid Equilibrium Method (Permporometry)}

This method is based on the phenomenon of capillary condensation of liquids in micropores, which is the basis of one of the most popular methods for the characterization of the pore size distribution in porous media. Permporometry is the only method known so far [9] suitable for the determination of size distribution of the active pores with diameters ranging from about $1.5 \mathrm{~nm}$ to $0.1 \mu \mathrm{m}$ in porous media, particularly those with an asymmetric and/or composite structure. This method is relatively new technique, is based on the controlled blocking of the pores by capillary condensation and simultaneous measurement of the gas diffusion flux through the remaining open pores. There are two different approaches of the method [10].

\subsubsection{Liquid Displacement Permporometry (LDP) [11]}

The liquid displacement method is commonly used to determine pore sizes and pore size distributions of a membrane because it is close to (ultra)filtration practice: dead-end pores are not evaluated; the membrane is characterized in wet conditions; in addition the pressure is kept as low as possible and thus no alteration of the membrane occurs [12].

This method was first described by Erbe [4] and Kesting [13] and further developed by Capannelli et al. $[11,14]$. It is based on the measurement of the flux of a displacing liquid through the membrane as a function of the pressure applied. Thus, this method is similar to the bubble point method but a liquid in the pore is displaced by another liquid instead of gas. From the flux-pressure curve the pore size distribution is calculated using the Hagen-Poiseuille equation. Following assumptions are used for the calculation of pore size distribution.

a. The pores are cylindrical.

b. The pores are parallel to each other and not interconnected and thus are straight through the whole membrane layer.

c. The pores all have length $l$, where $l$ is usually taken to be the thickness of the membrane (or thickness of the membrane skin layer in the case of an asymmetric membrane).

With assumption $\mathrm{A}$ and $\mathrm{B}$, pore density function $N\left(r_{\mathrm{p}}\right)$ can be calculated from the 
increase in the measured flux $\left(d \varphi_{\mathrm{s}}\right)$ upon the increase in transmembrane pressure $(d \Delta P$ ) using the following Hagen-Poiseuille equation.

$$
N\left(r_{\mathrm{p}}\right)=\frac{8 \eta l}{\pi r_{\mathrm{p}}^{4}} \frac{d \varphi_{\mathrm{s}}}{d \Delta P}
$$

where $\eta$ is the viscosity of the displacing liquid. If $l$ is not known, a relative pore size distribution can be calculated.

The results obtained by the liquid displacement become incorrect if the pores are connected to each other or if there is a resistance against flow in membrane sub-layer or in the measurement apparatus. As a result of the additional resistance, the estimated pore size distribution shifts toward smaller pores and a larger number of pores. To overcome this, two methods have been suggested by Gijsbertsen-Abrahamse et al. [15]: either by estimating the sub-layer resistance by determining the number of active pores or by repeated measurement of the flux-pressure curves with different levels of coverage of the membrane surface.

\subsubsection{Diffusional Permoporometry (DP) [17]}

Diffusional permoporometry (DP) was first used by Katz [16, 17]. Later on, refinements to the technique have been suggested by many authors $[9,10,18]$. In this method, the Kelvin equation given in Section 1.3 is used combined with the diffusive vapor transport through the open pores. The measurement starts from the relative vapor pressure $p / p_{0}=1$, where all the pores are filled with liquid and the vapor transport is impossible. By reducing the vapor pressure progressively, more pores will be emptied and become available for vapor transport. Thus, measuring vapor flow rates at progressively decreasing vapor pressures, pore size distribution can be obtained.

In this method, a fluid " $A$ ", which completely wets the membrane, is used to fill the pores. A second fluid " $\mathrm{B}$ " (gas), immiscible in the " $\mathrm{A}$ ", is then permeated through the membrane. The permeate flow rate is measured at various transmembrane pressures. Thus, this is an extension of the bubble point method.

Again the pore size and the transmembrane pressure difference are related to each other by Cantor's equation. Again the Hagen-Poiseuille equation is used to calculate the pore density function.

TO ACCESS ALL THE 43 PAGES OF THIS CHAPTER, Visit: http://www.desware.net/DESWARE-SampleAllChapter.aspx 


\section{Bibliography}

A. Viallat - M.M. Margulies (2000) "Porous structure of membranes of an acrylonitrile copolymer. Porosity, ${ }^{1}$ H-NMR permeability" Eur. Phys. J. E, 2, 117-123.

Albrecht, T.R., Dovek, M.M., Lang, C.A., Grutter, P., Quate, C.F., Kuan, S.W.J., Frank, C.W., Pease, R.F.W. (1988) "Imaging and modification of polymers by scanning tunneling and atomic force microscopy" J. Appl. Phys. 64, 1178.

Altena, F.W., Knoef, H.A.M., Heskamp, H., Bargeman, D., Smolders, C.A. (1983) "Some comments on the applicability of gas permeation methods to characterize porous membranes based on improved experimental accuracy and data handling" Journal of Membrane Science, 12(3), 313-322.

Barrett EP, Joyner LG, Halenda PP. (1951). "The determination of pore volume and area distribution in porous substances. I. Computations from nitrogen isotherms", J Am Chem Soc. 73, 373-80.

Bechhold, H. Schlesinger, M., Silbereisen, K., Maier, L., Nurnberger, W., (1931)."Pore diameters of ultrafilters", Kolloid Z., 55, 172

Belfer S, Fainchtain R, Purinson Y, Kedem OJ. (2000) "Surface characterization by FTIR-ATR spectroscopy of polyethersulfone membranes-unmodified, modified and protein fouled" J Membr Sci. 172,113-124.

Bessieres A, Meireles M, Coratger R, Beauvillain J, Sancbez V (1996). "Investigations of surface properties of polymeric membranes by near field microscopy" J Membr Sci., 109,271-284.

Binnig, G., Quate C. F. (1986) "Atomic Force Microscope" Phys. Rev. Lett. 56, 930-933.

Bowen, WR, Hilal, N, Lovitt, RW, Williams, PM. (1996) "Atomic force microscope studies of membranes: Surface pore structures of Cyclopore and Anopore membranes" J Membr Sci., 110, 233-238.

Brun, M., Lallemand, A., Quinson, J.F., Eyraud, C. (1977) "A new method for the simultaneous determination of the size and the shape of pores: the thermoporometry", Thermochim. Acta 21, 59.

Cao G. Z., J. Meijerink, H. W. Brinkman, A. J. Burggraaf, (1993). "Permporometry Study on the Size Distribution of Active Pores in Porous Ceramic Membranes,” J. Membrane Sci., 83 221-235

Capannelli, G., I. Becchi, A. Bottino, P. Moretti, S. Munari, (1987) "Computer Driven Porosimeter for Ultrafiltration Membranes,” Proc. Studies in Surface Science and Catalysis, 283.

Capannelli, G., Vigo F., Munari, S. , (1983) "Ultrafiltration membranes - characterization methods", Journal of Membrane Science, 15(3), 289-313

Carrington A (1962) "The Principles of Electro-spin Resonance" Endeavour 21, 51-57.

Chen, Hongmin, Hung, Wei-Song, Lo, Chia-Hao, Huang, Shu-Hsien, Cheng, Mei-Ling, Liu, Guang, Lee, Kueir-Rarn, Lai, Juin-Yih, Sun, Yi-Ming, Hu, Chien-Chieh, Suzuki, R., Ohdaira, T., Oshima, N., Jean, Y. C. (2007) "Free-Volume Depth Profile of Polymeric Membranes Studied by Positron Annihilation Spectroscopy: Layer Structure from Interfacial Polymerization" Macromolecules 40(21), 7542-7557.

Christopher L. Glaves, Gregory C. Frye, Douglas M. Smith, C. Jeffery Brinker, Abhaya Datye, Antonio J. Ricco, Stephen J. Martin (1989) "Pore structure characterization of porous films" Langmuir 5(2), 459-466.

Chung, T. S., Jiang, L. Y., Li, Y., Kulprathipanja, S., (2007) "Mixed matrix membranes (MMMs) comprising organic polymers with dispersed inorganic fillers for gas separation" Prog. Polym. Sci. , 32, 483-507.

Cosentino C, Amato F, Ferrari M (2007) in "BioMEMS and Biomedical Nano Technology" , eds. Ferrari M, Lee AP, Lee J, Springer US, , pp. 203.

Cuperus, F.P., Bargeman, D., Smolders, C.A. (1992) "Permporometry: the determination of the size distribution of active pores in UF membranes", Journal of Membrane Science, 71 (1-2), 57-67.

DAI, Qing Wen, XU, Zhi Kang, WU, Jian (2004) "A Novel Approach for the Surface Modification of Polymeric Membrane with Phospholipid Polymer" Chinese Chemical Letters Vol. 15, No. 8, pp 993-996.

Davis, P.J., Smith, D.M. (1989) "Using NMR Spectroscopy to Analyze the Pore Structure of Coatings", 
TAPPI. Journal, 72(5), 85-89.

Elimelech M, Zhu X, Childress AE, Hong S (1997). "Role of membrane surface morphology in colloidal fouling of cellulose acetate and composite aromatic polyamide reverse osmosis membranes" J Member Sci., 127, 101-109.

Elimelech, M., Chen, W.H., Waypa, J.J. (1994). "Measuring the zeta (electrokinetic) potential of reverse osmosis by a streaming potential analyzer", Desalination, 95, 269-286.

Erbe, F., (1933). "Die Bestimmung der Porenverteilung Nach Ihrer Groe in Filtern und Ultrafiltern", Kolloid-Zeitschrift, 63, 277

Gall, M.J., Hendra, P.J., Peacock, C.J., Cudby, M.E.A., Willis, H.A. (1972) "Laser-Raman spectrum of polyethylene: Part 1. Structure and analysis of the polymer", Polymer, 13(3), 104-108.

Gary C. Rex, Shulamith Schlick (1987) "Study of polymer gels using paramagnetic probes: E.S.R. spectra of $\mathrm{Cu}^{2+}$ in reversible polyacrylamide gels" Polymer 28(12), 2134-2138.

Gijsbertsen-Abrahamse, A.J., Boom, R.M., Padt, A. van der, (2004). "Why liquid displacement methods are sometimes wrong in estimating the pore-size distribution". AIChE Journal 50, ISSN 0001-1541, 1364 $-1371$.

Griffith, O. Hayes, Waggoner, A. S. (1969) "Nitroxide free radicals: spin labels for probing biomolecular structure" Acc. Chem. Res., 2 (1), 17-24.

Haines, N.F., Bell, J.C., McIntyre, P.J., (1978) "The application of broadband ultrasonic spectroscopy to the study of layered media". J. Acoust. Soc. Am 64, 1645-1651.

Hazri, A., Vaidya, A. M., (1995) "A new computational technique for the analysis of diffusion permoporometric data for asymmetric membranes", Journal of Membrane Science 101(1-2), 61-66.

Hill, A. J., Weinhold, S., Stack, G. M., Tant, M. R. (1996) "Effect of copolymer composition on free volume and gas permeability in poly(ethylene terephthalate)-poly(1,4 cyclohexylenedimethylene terephthalate) copolyesters" European Polymer Journal 32(7), 843-849.

Hirose M, Itoh H, Minamizaki Y, Kamiyama Y (1996) "Proceedings of the International Congress on Membranes and Membrane Process", Yokohama, Japan 18-23 August, pp 178.

Ho J., Santerre, J.P., Matsuura, T., (2000) "The effect of Fluorinated Surface Modifying Macromolecules on Polyethersulfone Membranes", J. Biomat. Sci., Polym. Ed., 11 (10), 1085-1105.

Jean YC, Malton PE, Schrader DM (2003) "Principles and Applications of Positron and Positronium Chemistry", World Scientific Publishers, New Jersey.

K. C. Khulbe, B. Kruczek, G. Chowdhury, S. Gagné, T. Matsuura, S. P. Verma (1996) "Characterization of membranes prepared from PPO by Raman scattering and atomic force microscopy" Journal of Membrane Science, 111(1), 57-70.

Katleen Boussu, Jérémie De Baerdemaeker , Charles Dauwe , Marc Weber , Kelvin G. Lynn, Diederik Depla, Steliana Aldea, Ivo F. J. Vankelecom , Carlo Vandecasteele, Bart Van der Bruggen. (2007) "Physico-Chemical Characterization of Nanofiltration Membranes" ChemPhysChem 8(3), 370-379.

Katz MG, (1982) "Measurement of Pore Size Distribution in Microporous Filters and Membranes" In R. J. Wakeman (Ed.) Congress III, The Filtration Society, Uplands Press, Croydon, Vol. II, 508.

Katz,M.G., Baruch, G., (1986) "New Insights Into The Structure Of Microporous Membranes Obtained Using A New Pore Size Evaluation Method", Desalination, 58, 199-211

Kesting, R. E. (1990) "The four tiers of structure in integrally skinned phase inversion membranes and their relevance to the various separation regimes ", Journal of Applied Polymer Science 41(11-12), 27392752.

Kesting, R. E., (1971).Synthetic Polymeric Membranes, McCraw Hill, New York.

Kesting, R.E., Engdahl, M., Stone Jr., W., (1969). "The application of scanning electron microscopy to membrane morphology", J. Macromol. Sci. A3 (1),157-167.

Keurentjes, J. T. F., Harbrecht, J. Brinkman, G., D., Hanemaaijer, J. H., Cohen Stuart, M. A., van't Riet, 
K. (1988) "Hydrophobicity measurements of microfiltration and ultrafiltration membranes" Journal of Membrane Science 47(3), 333-344.

Khulbe KC, Feng CY, Matsuura (2008) "Synthetic Polymeric Membranes: Characterization by Atomic Force Microscopy" Springer.

Khulbe KC, Matsuura T, Kim HJ (2000) "Raman scattering of PPO membranes J Appl Polym Sci". Journal of Applied Polymer Science 77(11), 2558-2560.

Khulbe KC, Matsuura T, Lamarche G, Kim HJ, (1997). "The morphology characterisation and performance of dense PPO membranes for gas separation" J Membr Sci 135, 211-223.

Khulbe KC. Matsuura T. (2000) "Characterization of Synthetic membranes by Raman ... and atomic force microscopy; a review", Polymer; 41, 1917-1935.

Khulbe, K. C. , Chowdhury, G. , Matsuura, T. Lamarche, G. (1997) "Characterization of PPO [poly(phenylene oxide)] powder and membranes from it by ESR technique" Journal of Membrane Science, 123(1), 9-15.

Khulbe, K. C. , Matsuura, T. , Feng, C. Y. , Lamarche, G., Lamarche, A. -M. (2002) "Characterization of ultrafiltration membrane prepared from poly ethersulfone by using electron spin resonance technique" Separation and Purification Technology 29(1), 15-22.

Khulbe, K. C., Matsuura, T., Lamarche, G., Lamarche, A. -M. (2000) "X-ray diffraction analysis of dense PPO membranes" Journal of Membrane Science 170(1), 81-89.

Khulbe, K. C., Chowdhury, G., Kruczek, B., Vujosevic, R., Matsuura, T. Lamarche G. (1997) "Characterization of the PPO dense Membrane prepared at different temperatures by ESR, atomic force microscope and gas permeation" Journal of Membrane Science , 126(1), 115-122.

Kim, Soon Sam, Yavrouian, Andre H., Liang, Ranty H., (1993) "Segmental mobility and free-volume decay of poly(phenyl methacrylate). An EPR study" Journal of Polymer Science Part B: Polymer Physics 31, 495-499.

Kim, T. H., Koros, W. J., Husk, G. R., O'Brien, K. C. (1988) "Relationship between gas separation properties and chemical structure in a series of aromatic polyimides" Journal of Membrane Science, 37(1), 45-62.

Koutake, M., Uchida, Y., Kimura, Sagara, T., Watanabe, Y. A., Nakao, S. (1985) "Observation of UF membranes pores through a scanning electron microscope and their pure water fluxes", Maku, 10,310312.

Kruk M., Jaroniec M., (2002) “Determination of Mesopore Size Distri- butions from Argon Adsorption Data at 77 K,” J. Phys. Chem. B, 106, 4732-4739

Kulkarni, Sandeep, Krause, Sonja, Wignall, G. D. (1994) "Investigation of the Pore Structure and Morphology of Cellulose Acetate Membranes Using Small-Angle Neutron Scattering (SANS). 2. Ultrafiltration and Reverse-Osmosis Membranes" Macromolecules, 27 (23), 6785-6790.

Kulkarni, Sandeep, Krause, Sonja, Wignall, G. D., Hammouda, B. (1994) " Investigation of the Pore Structure and Morphology of Cellulose Acetate Membranes Using Small-Angle Neutron Scattering. 1. Cellulose Acetate Active Layer Membranes" Macromolecules, 27 (23), 6777-6784.

Kunal Pal, Ajit K. Banthia, Dipak K. Majumdar. (2007) "Preparation and Characterization of Polyvinyl Alcohol-Gelatin Hydrogel Membranes for Biomedical Applications" AAPS PharmSciTech; 8 (1) Article 21.

Landsry, MR., (2005) "Thermoporometry by differential scanning calorimetry: experimental considerations and applications" Thermochimica Acta , 433(1-2), 27-50.

Li, Jianxin , Sanderson, R. D. , Jacobs, E. P. (2002) "Non-invasive visualization of the fouling of microfiltration membranes by ultrasonic time-domain reflectometry" Journal of Membrane Science 201(1-2), 17-29.

Loeb, S., Sourirajan, S., (1962)."Sea Water Demineralization by Means of an Osmotic Membrane", Advances in Chemistry Series, 38, 117 
Malcolm L. Williams, Robert F. Landel, John D. Ferry (1955) "The Temperature Dependence of Relaxation Mechanisms in Amorphous Polymers and Other Glass-forming Liquids" J. Am. Chem. Soc., 77 (14), 3701-3707.

Merin, U., Cheryan, M. (1980) "Ultrastructure of the surface of a polysulfone ultrafiltration membrane", $J$. Appl. Polym. Sci. 25, 2139-2142.

Michaels, A.S., (1980). "Analysis and prediction of sieving curves for ultrafiltration membranes: a universal correlation", Sep. Sci. Technol. 15, 1305.

Miller WG (1976) "Spin Labeled Synthetic Polymers. Molecular Biology Spin Labeling II:Ttheory and Application" Academic Press, New York, pp 173.

Moore, Theodore T., Koros, William J. (2005) "Non-ideal effects in organic-inorganic materials for gas separation membranes" Journal of Molecular Structure 739(1-3), 87-98.

Mulder, M., Dordrecht, (1996). "Basic Principles of Membrane Technology", 2nd ed., Boston : Kluwer Academic Publishers.

Munari, S., Bottino, A., Moretti, P., Capannelli, G., Becchi, I., (1989) "Permoporometric study on ultrafiltration membranes", Journal of Membrane Science 41(15), 69-86.

Nakanishi H, Wang SJ., Jean YC. (1988) "Positron Annhilation studies of fluids" in Sharma SC. Editor, Singapore, world scientific. p292.

Nakao, Shin-ichi (1994). "Determination of pore size and pore size distribution: 3. Filtration membranes" Journal of Membrane Science. 96(1-2), 131-165

Patrick A. C. Gane, Cathy J. Ridgway, Esa Lehtinen, Rustem Valiullin, Istvan Furó, Joachim Schoelkopf, Hannu Paulapuro, John Daicic (2004)."Comparison of NMR Cryoporometry, Mercury Intrusion Porosimetry, and DSC Thermoporosimetry in Characterizing Pore Size Distributions of Compressed Finely Ground Calcium Carbonate Structures" Ind Eng Chem Res 43(24),7920-7927.

Patterson, D.A., Havill, A., Costello, S., See-Toh, Y.H., Livingston, A.G., Turner A., (2009) "Membrane Characterisation by SEM, TEM and ESEM: The Implications of Dry and Wetted Microstructure on Mass Transfer through Integrally Skinned Polyimide Nanofiltration Membranes", Separation and Purification Technology, 66, 90-97.

Pereira Nunes, S., Peinemann, K. V., (1992). "Ultrafiltration Membranes from PVDF/PMMA Blends", J. Membrane Sci., 77, 25

Rafat, Mehrdad, De, Dibyendu, Khulbe, K. C., Nguyen, Thanh, Matsuura, T. (2006) "Surface characterization of hollow fiber membranes used in artificial kidney" J Appl Polym Sci. 101(6), 43864400 .

Reinsch, Veronika E., Greenberg, Alan R., Kelley, Stephen S., Peterson, Rorik Bond, Leonard J. (2000) "A new technique for the simultaneous, real-time measurement of membrane compaction and performance during exposure to high-pressure gas" Journal of Membrane Science 171(2), 217-228.

Riley, R., Gardner, J.O., Merten, U. (1964). "Cellulose acetate membranes: Electron microscopy of structure" Science 143(3608), 801-803.

Rosa, M.J. , de Pinho, M.N. (1997) "Membrane surface characterisation by contact angle measurements using the immersed method" Journal of Membrane Science 131(1-2), 167-180.

Satyanarayana, S.V., Subrahmanyam, V.S., Verma, H.C., Sharma, A., Bhattacharya, P.K. (2006) "Application of positron annihilation: Study of pervaporation dense membranes" Polymer 479(4), 13001307.

Schossig-Tiedemann, M., Paul, D. (2001) "Improved preparation of membrane surfaces for fieldemission scanning electron microscopy" Journal of Membrane Science 187(1-2), 85-91.

Shantarovich, P., Azamatova, Z. K., Novikov, Yu. A., Yampolskii, Yu. P. (1998) "Free-Volume Distribution of High Permeability Membrane Materials Probed by Positron Annihilation" Macromolecules, 31(12), 3963-3966.

Shantarovich, V. P. , Kevdina, I. B. , Yampol'skii, Yu. P. (2000) "Evaluation of nonuniformity of 
polymeric membrane materials by positron annihilation technique" High Energy Chemistry 34, 265-272.

Sheldon F. Oppenheim, Garry R. Buettner, Jonathan S. Dordick, V.G.J. Rodgers (1994) "Applying electron paramagnetic resonance spectroscopy to the study of fouling in protein ultrafiltration" Journal of Membrane Science , 96(3), 289-297.

Singh S, Khulbe KC, Matsuura T, Ramamurthy, P., (1998). "Membrane characterization by solute transport and atomic force microscopy", Journal Of Membrane Science 142(1), 111-127.

Sloan, James M (2004) "Characterization of the transport properties in elastomeric polymer membranes by FT-IR-ATR ", ANTEC Conference Proceedings vol. 2, pp. 2386-2389.

Smolders, C.A., Vugteveen, E., (1985) "New characterization methods for asymmetric ultrafiltration membranes". Mater. Sci. Synth. Membr., 327-338.

Stone, T. J., Buckman, T., Nordio, P. L., McConnell, H. M. (1965) "Spin-labeled biomolecules". Proc. Natl. Acad. Sci. U.S.A., 54, 1010-1017.

Suk D, (2005) "Development of Surface Modifying Macromolecule Blended Polyethersulfone Membranes for Vacuum Membrane Distillation" Ph.D. Thesis, Department of Chemical Engineering, University of Ottawa.

Tao SJ. (1972) "Positronium annihilation in molecular substance", J. Chem. Phys. 56, 5499-5510.

Tomás E. Gómez Álvarez-Arenas (2003) "Air-coupled ultrasonic spectroscopy for the study of membrane filters" Journal of Membrane Science 213(1-2), 195-207.

Tung, Kuo-Lun, Jean, Yan-Ching, Nanda, Dipankar , Lee, Kueir-Rarn, Hung, Wei-Song , Lo, ChiaHao , Lai, Juin-Yih (2009) "Characterization of multilayer nanofiltration membranes using positron annihilation spectroscopy" Journal of Membrane Science 343(1-2), 147-156.

Wang Y, Yin S, Ren L, Zhao L. (2009) "Surface characterization of the chitosan membrane after oxygen plasma treatment and its aging effect". Biomed Mater. 4(3), 035003.

Wang, Y. Y., Nakanishi, H., Jean, Y. C., Sandreczki, T. C. (1990) "Positron annihilation in amine-cured epoxy polymers—pressure dependence" J Polym Sci, Polym Phys B 28 (9), 1431-1441.

Wienk, I. M., van den Boomgaard, Th., C. Smolders, A. (1994) "The formation of nodular structures in the top layer of ultrafiltration membranes" Journal of Applied Polymer Science, 53(8), 1011-1023.

Yi Fang, Vu Anh Pham, Takeshi Matsuura, J. P. Santerre and Roberto M. Narbaitz (1994) Effect of surface-modifying macromolecules and solvent evaporation time on the performance of polyethersulfone membranes for the separation of chloroform/water mixtures by pervaporation J Appl Polym Sci Volume 54 issue 12 pages 1937-1943.

Yin, Htwe Htwe, Yin, Zejie, Ma Weitao, Zhu, Daming (2005) "A Review of Studies of Polymeric Membranes by Positron Annihilation Lifetime Spectroscopy" Plasma Science \& Technology, 7(5), 30623064.

Zeman L, Denault, Lauraine (1992) "Characterization of microfiltration membranes by image analysis of electron micrographs. Part II. Functional and morphological parameters" J. Membrane Sci. 71. 233.

Zeman, L., Tkacik, G., Le Parlouer, P., (1985) "Pore volume distribution in UF membranes", Mater. Sci. Synth. Membr. p. 339.

Zeman, Leos., Denault, Lauraine (1992) "Characterization of microfiltration membranes by image analysis of electron micrographs Part I. Method development" Journal of Membrane Science 71(3), 22131.

Zubov, P.I., Voronkov, V.A., Sukharev, L.A. (1968) "Effect of solvent and polymer solid interactions on the structure and properties of polystyrene", Vysokomol Soedin Ser. B 10 (2) 92-95 (C.A. 68, 3606g)

\section{Biographical Sketches}

Kailash Khulbe is a graduate of Agra University, Agra, India, where he obtained the B.Sc., M, Sc., and Ph. D. degree. .He joined the Chemical Engineering Department, University of Ottawa, Canada in 1967 
and stated his research in the field of catalysis, coal conversion and tar sands. At present he is working on the on the Synthetic Membranes and Characterization of membranes. His main interest is on the characterization of membranes by AFM, IR, RS, and ESR etc. He has published over 150 (membranes and heterogeneous catalysts) papers in referred journals, coauthored 1 book (AFM of synthetic membranes) and wrote 2 chapters for two books related with synthetic membranes, and many reviews.

Chaoyang Feng received his B.Sc. (1987) and M.Sc. (1990) from the Chemical Engineering Department of Donghua University (China Textile University). He received his $\mathrm{PhD}$ at the Chemical and Biological Engineering Department of University of Ottawa (2009). Since 1990, he started to study on membrane technology on hollow fiber membrane for blood separation and artificial kidney. In 1998, he came to Industrial Membrane Research Institute of University of Ottawa to continue his membrane research under supervision of Dr. T. Mastuura. He was awarded NSERC Post-graduate Student Scholarship and Excellent Student Scholarship of Canada (2005-2008). He was also awarded NAMS Travel Award of North America Membrane Society (2005). Until now, He has published over 38 papers in referred journals, coauthored 1 book (AFM of synthetic membranes) and wrote 2 chapters for two books related with synthetic membranes, one patent and many reviews.

Takeshi Matsuura received his B.Sc. (1961) and M.Sc. (1963) from the Department of Applied Chemistry at the Faculty of Engineering, University of Tokyo. He received his Doktor-Ingenieur at the Institute of Chemical Technology of the Technical University of Berlin (1965). He worked at the National Research Council of Canada from 1969 until he joined the University of Ottawa in 1992 as a professor and the chair holder of the British Gas/NSERC Industrial Research Chair. He also served as the director of the Industrial Membrane Research Institute (IMRI) of the University of Ottawa until he retired in 2002. He is currently professor emeritus at the Department of Chemical and Biological Engineering of the University of Ottawa. 